\title{
Peter WesthofF
}

\section{Wie Zellen verschieden werden - Der Sonderforschungsbereich 590}

Die Geschichte des Lebens ist die Geschichte des Übergangs vom Einfachen zum Komplizierten. Waren zunächst nur einzelne Zellen vorhanden, wie wir sie noch heute in Form der Bakterien wiederfinden, so entstand später die Vielzelligkeit. Alle Organismen, die wir mit dem unbewaffneten Auge erkennen können, seien es Tiere, Pflanzen oder Pilze, bestehen aus vielen Zellen, die zu Funktionseinheiten in Form von Geweben oder Organen zusammengefasst sind. So sind beispielsweise die Blätter einer Pflanze für die Fotosynthese verantwortlich. Man erkennt beim Blick durch ein Mikroskop sofort, dass das Blatt aus verschieden gestalteten Zellen mit vermutlich unterschiedlichen Aufgaben aufgebaut ist (Abb. 1).

Am Anfang des Werdegangs einer Pflanze, eines Tieres oder eines Pilzes steht eine einzige Zelle, die befruchtete Eizelle, auch Zygote genannt. Die Entwicklung eines vielzelligen Organismus ist mit zwei Grundprozessen verknüpft. Die befruchtete Eizelle und ihre Abkömmlinge teilen und vermehren sich, was wir mit dem Begriff Zellproliferation belegen. Die durch Zellteilung entstandenen Tochterzellen bleiben jedoch nicht gleich, sondern werden verschieden und üben schließlich unterschiedliche Funktionen aus. Das Verschiedenwerden von Zellen bezeichnen wir als Differenzierung. Seit seiner Gründung im Jahr 2001 war und ist es das Ziel des Sonderforschungsbereichs (SFB) 590 „Inhärente und Adaptive Differenzierung“, Differenzierung bei Tieren, Pflanzen und Pilzen mechanistisch verstehen zu lernen.

Differenzierung wird in erster Annäherung intern gesteuert (inhärente Differenzierung). Der werdende Organismus besitzt eine Art eingebautes Entwicklungsprogramm, das festlegt, wie sich die Zellen in Raum und Zeit zu verändern haben. Differenzierung kann dadurch eingeleitet werden, dass die Ausgangszelle sich ungleich teilt und die beiden Tochterzellen damit in ihrem Zellinhalt unterschiedliche Entwicklungsdeterminanten enthalten. Viel häufiger aber wird Differenzierung durch Signale induziert, die Zellen in der Nachbarschaft oder der Ferne aussenden. Die zur Differenzierung befähigten Zellen nehmen diese Signale wahr und beginnen, sich unterschiedlich weiterzuentwickeln.

Der inhärenten steht die adaptive Differenzierung gegenüber. Äußere Faktoren steuern Differenzierungsprozesse oder führen zur Umdifferenzierung bereits differenzierter Zellen. Bei Pflanzen ist das Licht ein wichtiger, äußerer Steuerfaktor. Entwickelt sich die Pflanze beispielsweise im vollen Sonnenlicht, sind ihre Blätter viel kräftiger und enthalten mehr Parenchymzellen als im Schatten.

Äußere Faktoren können aber auch der belebten Welt entstammen, wie Bakterien oder Pilze. Diese befallen andere Lebewesen, entreißen ihnen die Nährstoffe und vermehren 


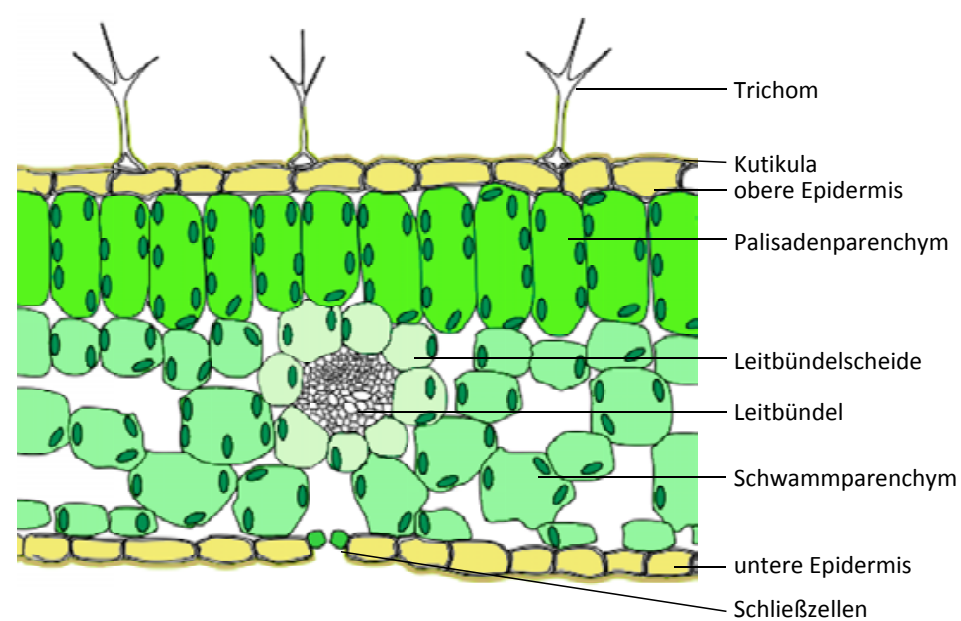

Abb. 1: Aufbau eines Laubblattes - ein Schema

Der Querschnitt des Laubblattes einer höheren Pflanze, wie er sich beim Blick durch ein Mikroskop erschließt, ist hier schematisch wiedergegeben. Das Blatt ist oben und unten durch eine spezielle Zellschicht, die Epidermis, abgeschlossen. Auf die Epidermis aufgelagert ist eine wachsartige Schicht, die Kutikula, die mit den Zellen der Epidermis verhindert, dass das Blatt bei Sonneneinstrahlung zu viel Wasser verliert. Das Sonnenlicht wird aber benötigt, damit das Blatt seiner eigentlichen Funktion nachkommt, nämlich Fotosynthese zu betreiben. In der Fotosynthese wird das Sonnenlicht in chemische Energie umgewandelt und diese Energie für die Fixierung des Kohlendioxids der Luft in Kohlenhydrate wie Zucker oder Stärke verwendet. Für die Fotosynthese sind insbesondere die Zellen des Palisaden- und Schwammparenchyms zuständig, die dafür reichlich mit speziellen Zellorganellen, den Chloroplasten, ausgestattet sind. Das Kohlendioxid der Luft dringt durch die Spaltöffnungen mit ihren Schließzellen in das Blatt ein. Die Schließzellen können, wie ihr Name besagt, geschlossen werden, wenn das Blatt zu viel Wasser verliert. Die Produkte der Fotosynthese werden durch die Leitbündel in andere Pflanzenteile transportiert, die Leitbündel dienen aber auch dazu, Wasser und Nährstoffe in das Blatt aufzunehmen.

sich auf Kosten des Wirtsorganismus. Der angegriffene Organismus wehrt sich, indem er seine Zellen bewaffnet und damit umdifferenziert. Er kann aber auch die ,Taktik der verbrannten Erde“ verfolgen und die angegriffenen Zellen - mit dem Angreifer - absterben lassen.

Führt man sich das Endergebnis vor Augen, verlaufen Differenzierungsprozesse bei Tieren, Pflanzen und Pilzen sehr unterschiedlich. Eine ausdifferenzierte Herzmuskelzelle muss mechanische Arbeit verrichten; sie besitzt dafür lange Bündel spezieller Eiweißmoleküle (Proteine), die sich rhythmisch unter Energieverbrauch zusammenziehen und entspannen. Eine Nervenzelle ist dagegen in erster Linie ein Informationsüberträger; sie nimmt elektrische Signale von anderen Nervenzellen auf und leitet sie weiter. Dafür benötigt sie einen gänzlich anderen Satz an Proteinen als die Herzmuskelzelle. Die grünen Parenchymzellen des Blattes ziehen sich weder zusammen, noch leiten sie elektrische Signale weiter. Vielmehr sollen sie das Sonnenlicht ernten und in chemische Energie umwandeln (Abb. 1). 
Betrachtet man allerdings nicht das Endresultat von Differenzierungsprozessen, sondern wie sie eingeleitet und nach welchen Prinzipien sie gesteuert werden, ergibt sich eine Reihe von Gemeinsamkeiten. Daher ist es sinnvoll, Differenzierungsprozesse bei Pflanzen, Tieren und Pilzen gemeinsam im Rahmen eines Forschungsverbundes wie dem des SFB 590 zu untersuchen. Welche Prozesse Differenzierungsvorgängen gemeinsam sind und wie man sie untersuchen kann, sei im Folgenden erläutert.

\section{Differenzierung ist das Ergebnis differenzieller Genexpression}

Was eine Zelle und damit ein Organismus zu leisten vermag, ist durch sein Erbgut (Genom) vorgegeben. Das Genom eines Organismus besteht aus vielen Genen, die jeweils in einem mehrstufigen Prozess in Funktion übersetzt werden (Abb. 2).

In der Regel besitzen alle Zellen eines Organismus das gleiche Genom, aber nicht alle Erbanlagen (Gene) werden in jeder Zelle auch ausgeprägt. Vielmehr unterscheiden sich unterschiedlich differenzierte Zellen qualitativ und quantitativ in dem Gensatz, der in ihnen exprimiert wird. In den Muskelzellen unseres Herzens sind beispielsweise andere Gene aktiv als in den Gehirnzellen; wenn die gleichen Gene aktiv sein sollten, dann unterscheiden sie sich möglicherweise in ihrer Expressionshöhe (Abb. 3). Wir wissen heutzutage, dass differenzielle Genexpression für die unterschiedlichen Differenzierungswege verantwortlich ist und die Funktion einer ausdifferenzierten Zelle bestimmt. Jeder Differenzierungsprozess zeichnet sich damit durch ein charakteristisches Muster differenziell exprimierter Gene aus, das durch das gezielte An- oder Abschalten von Genen zustande kommt.

Will man einen Differenzierungsprozess in seiner Gesamtheit verstehen, müssen alle daran beteiligten Gene bekannt sein. Das erscheint einfach, ist es aber nicht, da Hunderte von Genen für die Verwirklichung einer bestimmten Differenzierungsleistung benötigt werden können. Erst nachdem man Genome in ihrer Gesamtheit entschlüsselt (sequenziert) hatte, konnte man mit einiger Verlässlichkeit abschätzen, wie viele Gene das jeweilige Genom enthält. Für den Menschen ergaben die Schätzungen 20.000 bis 25.000 Gene, für die Fruchtfliege 14.000 und für die Modellpflanze Arabidopsis 27.000.

Mit Hilfe dieser Genominformationen wurden so genannte Gen-Chips entwickelt, mit denen die Expression aller Gene eines Organismus im Verlauf eines Differenzierungsprozesses gemessen werden kann. Diese Gen-Chips enthalten auf kleinstem Raum Sonden für alle bekannten Gene eines Organismus. Die Sonden wirken wie ein Sortiment von Angelhaken. Jeder Angelhaken fischt nur die mRNAs seines entsprechenden Gens aus der zu untersuchenden mRNA-Population heraus und zählt, um im Bild zu bleiben, den Fangerfolg. Die DNA-Chiptechnik wird im Biologisch-Medizinischen Forschungszentrum (BMFZ) der Heinrich-Heine-Universität vorrätig gehalten und kann von den Mitgliedern des SFB genutzt werden. Gen-Chips werden übrigens auch im medizinischen Bereich als Diagnoseinstrument eingesetzt. So lassen sich beispielsweise Leukämien hinsichtlich ihres Genexpressionsmusters in verschiedene Subtypen klassifizieren, und der Arzt kann so eine maßgeschneiderte Therapie für jeden Leukämietyp auswählen.

In den letzten drei Jahren ist es im Bereich der RNA-Analytik zu einer weiteren methodischen Revolution gekommen. Es wurden Hochdurchsatz-Sequenzierungstechniken entwickelt, mit denen im Prinzip alle mRNAs einer Zelle, eines Gewebes oder eines Or- 


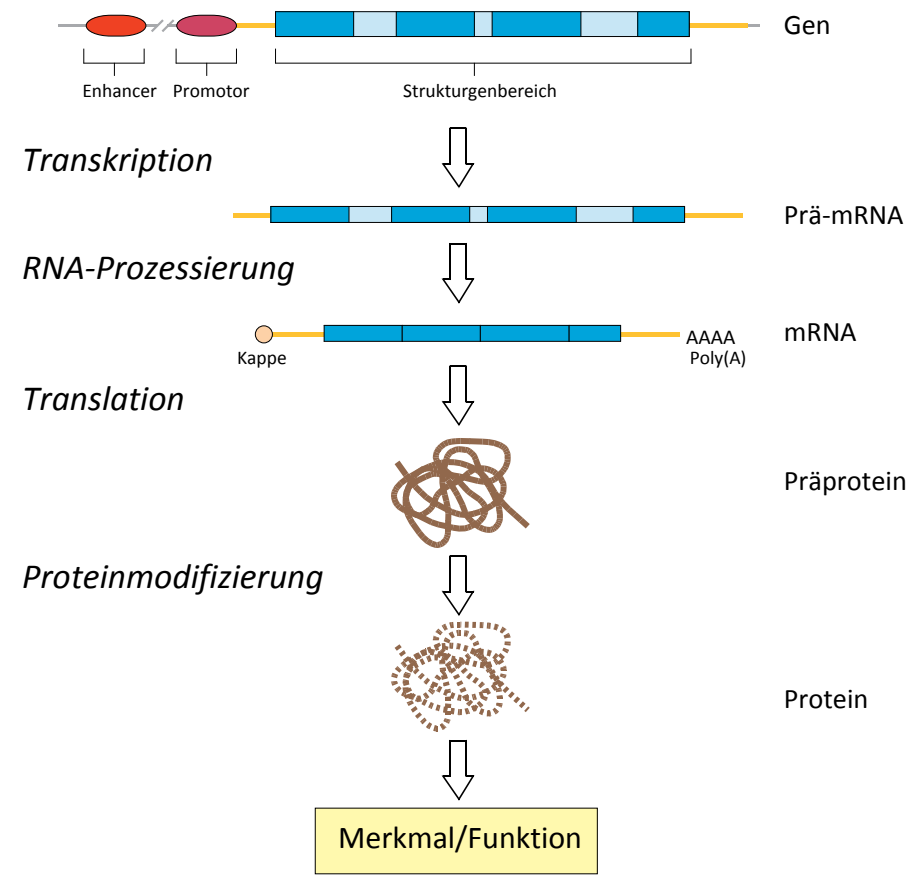

\section{Abb. 2: Die Expression eines Gens - vom Gen zum Merkmal}

Gene sind chemisch gesehen Desoxyribonukleinsäure (DNS; engl. DNA). Gene bestehen aus dem Strukturgenbereich, der die Information für ein Protein kodiert, und den vor oder hinter dem Strukturgen befindlichen Kontrollbereichen. Bei vielzelligen Organismen ist die kodierende Region (Exons) durch nichtkodierende Bereiche (Introns) unterbrochen. Der Bereich vor dem Gen enthält Regelelemente (Promotor und Enhancer), die bestimmen, wo im Organismus und wann die Geninformation abgelesen (transkribiert) wird. Wird ein Gen in Ribonukleinsäure (RNS; engl. RNA) übersetzt, entsteht zunächst eine Vorläufer-RNA (Prä-mRNA), die noch weiter prozessiert werden muss, um zur mRNA zu reifen. Dabei werden die Intronbereiche herausgeschnitten, so dass ein durchgehender kodierender Bereich entsteht, und die beiden RNA-Enden werden durch den Anbau einer Kappe beziehungsweise eines Poly $(A)$ Schwanzes verändert. Die reife mRNA (messenger RNA/Boten-RNS) wird zu den Ribosomen transportiert, die die Proteinsynthesefabriken der Zelle sind. Proteine sind aus Aminosäuren aufgebaut. An den Ribosomen wird die Information der mRNA entschlüsselt. Jeweils drei „Buchstaben“ (Basen) der RNA kodieren eine Aminosäure. Ist die mRNA abgelesen (translatiert) und das entsprechende Protein hergestellt, kann dieses noch weiter modifiziert werden. Beispielsweise können noch andere chemische Moleküle wie Zucker angefügt werden. Die reifen Proteine sind die Funktions- beziehungsweise Merkmalsträger der genetischen Information, sie sind sehr vielseitig. Als Enzyme katalysieren sie chemische Umsetzungen. Als Signalmoleküle nehmen sie Signale wahr und leiten diese an andere Proteine weiter. Als Transkriptionsfaktoren binden sie an die Kontrollbereich von Genen und schalten dadurch Gene an- oder ab. 
Herzmuskelzelle

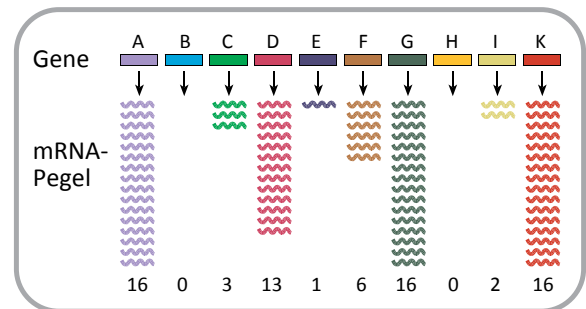

Nervenzelle

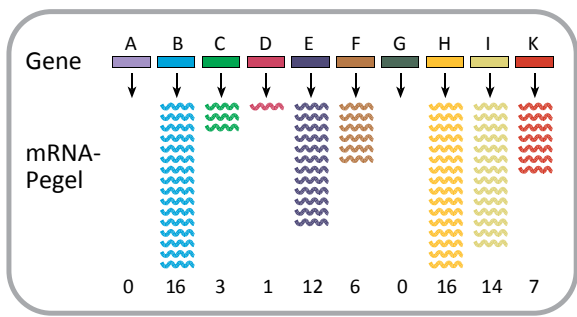

Abb. 3: Differenzielle Genexpression am Beispiel einer Herzmuskel- und Nervenzelle

Herzmuskel- und Nervenzellen besitzen das gleiche Genom, das - in diesem Beispiel - aus zehn Genen $(\mathrm{A}-\mathrm{K})$ bestehen soll. Die Gene werden jeweils in mRNA transkribiert, deren $\mathrm{Pe}$ gel sich untereinander, aber auch zwischen den beiden Zellen unterscheiden. Die Pegel der jeweiligen mRNA-Spezies werden durch relative Einheiten veranschaulicht. Anhand des Expressionsmusters lassen sich drei Klassen von Genen unterscheiden: (1) Die Gene A und G beziehungsweise $B$ und $\mathrm{H}$ werden ausschließlich in den Herzmuskel- beziehungsweise Nervenzellen exprimiert. (2) Die Gene D und K beziehungsweise $\mathrm{E}$ und I werden überwiegend in dem einen oder anderen Zelltyp abgelesen. Beide Gengruppen werden damit differenziell in Herzmuskel- und Nervenzellen exprimiert. (3) Die mRNA-Pegel der Gene C und F sind dagegen in beiden Zelltypen gleich hoch, sie werden damit konstitutiv, das heißt nicht-differenziell, ausgeprägt.

gans sequenziert und den zugehörigen Genen zugeordnet werden können. Je häufiger eine mRNA vorkommt, desto öfter wird sie auch sequenziert werden. Der Computer zählt die Häufigkeit des Auftretens jeder mRNA und erstellt ein quantitatives Genexpressionsprofil eines Differenzierungsprozesses. Auch diese neue Analysemethode wird gegenwärtig von Gruppen des SFB in Zusammenarbeit mit dem BMFZ etabliert. Dem SFB 590 steht damit für seine Arbeit das gesamte Repertoire an modernen Methoden für die Kartierung und Quantifizierung von Genexpressionsprofilen zur Verfügung.

\section{Signalketten und die Aktivierung der Transkription - Wie Gene differenziell angeschaltet werden}

Ob ein Gen exprimiert und das in ihm kodierte Merkmal ausgeprägt wird, kann prinzipiell auf jeder Stufe des Expressionspfades (Abb. 2) entschieden werden. Die Transkription ist jedoch die wichtigste Regelstufe. Wird das Produkt eines Gens nicht benötigt, wird der Pfad der Genexpression erst gar nicht betreten, und das Gen bleibt stumm. Die Transkription ist damit auch die wichtigste Kontrollinstanz für die Steuerung differenzieller Genexpression.

Wird der Differenzierungsprozess durch ein Signalmolekül induziert, das von einer anderen Zelle stammt, muss dieses Signal der Transkriptionsmaschinerie im Zellkern mitgeteilt werden, damit diese die entsprechenden Gene an- oder abschalten kann. Wie Abbildung 4 für die Aktivierung der Genexpression veranschaulicht, ist dies ein langer Weg, an dem viele Komponenten beteiligt sind, die passgenau zusammenarbeiten müssen.

Die Signalmoleküle werden von Rezeptoren, die sich in der Plasmamembran der Zelle befinden und ihren Antennenteil nach außen gerichtet haben, wahrgenommen. Bindet das 
Signalmolekül außen an den Rezeptor, wird das Signal - nicht das Signalmolekül selbst durch das Rezeptorprotein nach innen weitergeleitet. Chemisch gesehen verändert sich dabei die Form des Rezeptorproteins und der Rezeptor wird dadurch angeschaltet. Der aktive Rezeptor leitet das Signal in der Regel zunächst an andere Signalüberträger weiter, bevor es schließlich in die Transkriptionsmaschinerie des Zellkerns einmündet.

Die Signalüberträger sind Proteine, die sich selbst oder andere Moleküle chemisch verändern können oder aber als Transportmoleküle für einfache chemische Atome wie beispielsweise Calcium-Ionen wirken. Signalüberträger sind häufig in einer Art Stafette angeordnet, der Stab wird von einem zum anderen weitergereicht. Der letzte Signalüberträger der Kette schließlich übergibt die Botschaft an die Transkriptionsmaschinerie.

Die Transkriptionsmaschinerie ist ein komplizierter Apparat, der aus vielen Komponenten aufgebaut ist, die miteinander wechselwirken müssen, damit ein Gen abgelesen werden kann. Die Transkriptionsfaktoren sind die Spezifitätskomponenten der Transkriptionsmaschinerie. Sie werden durch die Signalkette aktiviert und können nun an die Steuerregionen (Enhancer/Promotor) der Zielgene binden. Dort leiten sie die Transkription dieser Gene ein (Abb. 4).

Enhancer vielzelliger Lebewesen bestehen häufig aus vielen Einzelelementen, an die jeweils unterschiedliche Transkriptionsfaktoren binden. In der Regel entscheidet nicht ein einzelner Transkriptionsfaktor darüber, ob das Gen aktiviert wird, sondern das Ensemble aller Faktoren, die an den Enhancer binden. Die Kombinatorik bestimmt damit die Spezifität der Genexpression, und es ist leicht vorstellbar, wie ein vielzelliger Organismus mit einer begrenzten Anzahl von Transkriptionsfaktoren eine Vielzahl von Genen gezielt steuern kann. Die Abbildung 5 illustriert beispielhaft, wie man die Expressionsspezifität von Enhancern experimentell sichtbar machen kann.

Die Signalwege, die zur Aktivierung von Differenzierungsgenen führen, sind in der Regel komplizierter als oben dargestellt. Das Konzept einer einfachen, linearen Signalkette entspricht meistens nicht der Wirklichkeit. Eher trifft das Bild eines Netzwerkes zu. Es können mehrere Signale empfangen werden, und die Signalwege sind miteinander verbunden beziehungsweise münden in einen gemeinsamen Knoten. Dort werden die Signale miteinander verrechnet und schalten dann die Zielgene an- beziehungsweise ab.

Will man verstehen, wie differenzielle Genexpression im Verlauf eines Differenzierungsweges reguliert wird, müssen die Komponenten der regulatorischen Netzwerke, das heißt die Signalüberträger und ihre Zielelemente in der Transkriptionsmaschinerie, identifiziert werden. Für diese Aufgabe wird ein breites Methodenspektrum benötigt, das insbesondere genetische Verfahren umfasst.

Zum Methodenspektrum gehört auch, dass man fremde oder modifizierte Gene beziehungsweise regulatorische DNA-Fragmente in den Versuchsorganismus einfügen und stabil in seinem Genom verankern kann. Zur Transformation von Pflanzen bedient man sich des Bodenbakteriums Agrobacterium tumefaciens, das wie ein trojanisches Pferd Erbgut in die Pflanzenzelle einschleust und an zufälliger Position im Genom einlagert. Bei der Maus ist man sogar in der Lage, Erbgut an einer definierten Position im Genom zu platzieren. 


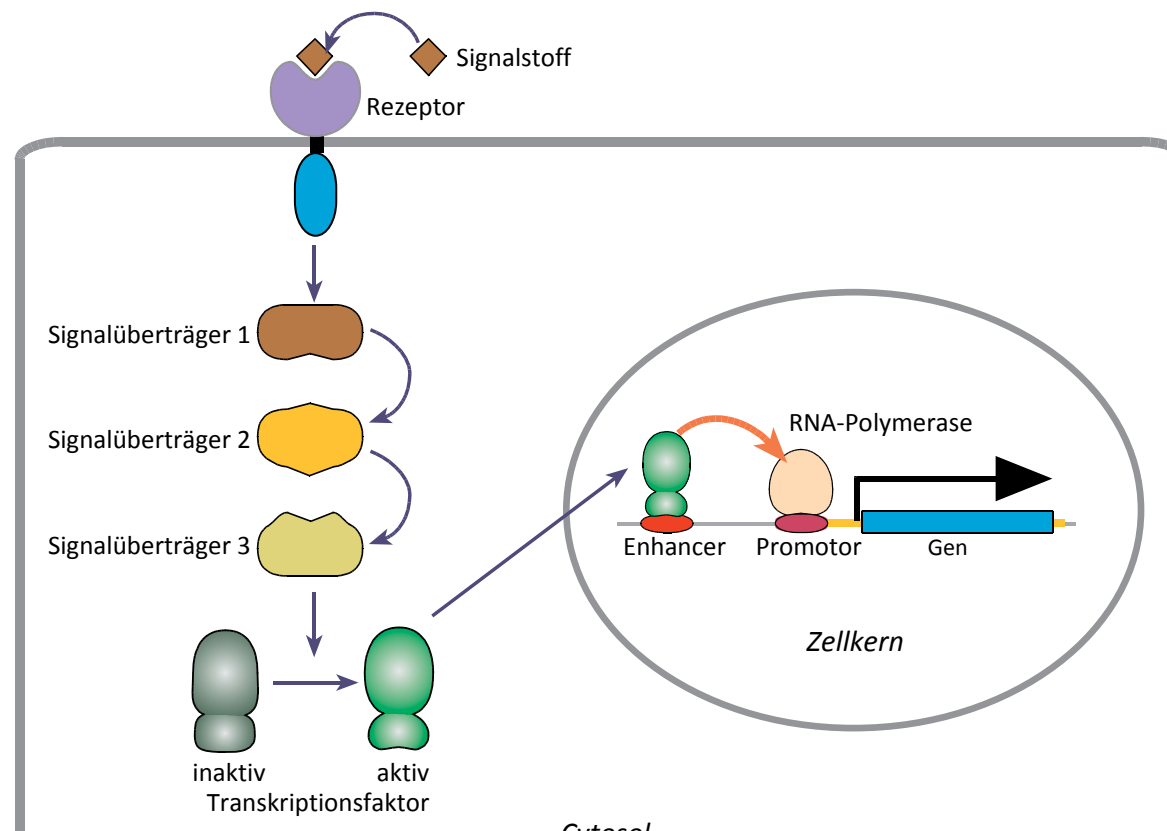

Cytosol

Abb. 4: Ein einfaches Schema für die Aktivierung von Genen durch eine Signalkette

Der membranständige Rezeptor besteht aus einem äußeren Teil mit Antennenfunktion und einem inneren Teil, der das Signal an die Signalübertragungskette weiterleitet. Diese Kette soll in unserem Beispiel aus drei verschiedenen Komponenten (Proteinen) bestehen, die passgenau aneinander andocken und sich dabei chemisch verändern. Solch eine dreigliedrige Kette kann zum Beispiel aus Proteinkinasen bestehen, die Phosphatmoleküle an Proteine heften. Die Signalkette aktiviert schließlich einen Transkriptionsfaktor, beispielsweise indem eine Phosphatgruppe an inn angeheftet wird oder er aus der Umklammerung durch einen Hemmfaktor befreit wird. Alternativ können Signalketten Transkriptionsfaktoren auch dadurch aktivieren, dass sie deren Abbau verhindern und dadurch erst die Anhäufung des Faktors in der Zelle ermöglichen. Der aktivierte Transkriptionsfaktor wandert in den Zellkern, bindet an den Enhancer des Zielgens und induziert dessen Transkription. Vereinfacht gesagt bewerkstelligt er das, indem er die Kopiermaschine der Transkription, die RNA-Polymerase, einfängt und an den Startpunkt des Gens dirigiert. Die RNA-Polymerase liest schließlich das Gen in RNA ab.

\section{Die Funktion und Dynamik regulatorischer Netzwerke der Differenzierung}

Mit der Identifizierung der Komponenten der regulatorischen Netzwerke eines Differenzierungsprozesses ist es nicht getan. Vielmehr muss man verstehen, wie sie wirklich funktionieren. Was passiert konkret in der Signalkette, wenn ein aktivierter Signalüberträger an den nachfolgenden Signalüberträger bindet, ihn chemisch verändert und dadurch aktiviert? Wie verändern sich die Formen dieser Signalüberträger, wenn man in Betracht zieht, dass ihre Bausteine, die Aminosäuren, flexibel miteinander wechselwirken und ihre Position 

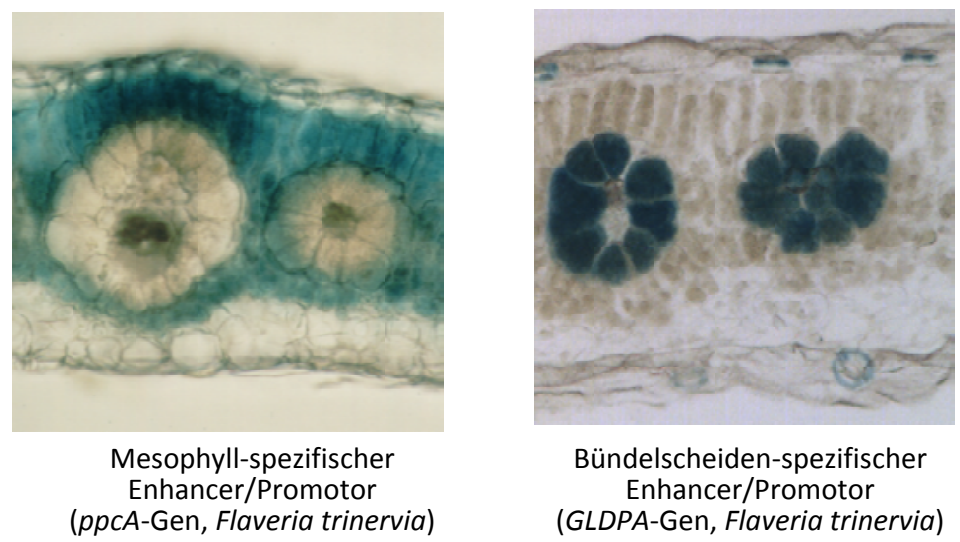

Abb. 5: Enhancer/Promotoren für spezifische Genexpression in den Mesophyll- und Bündelscheidenzellen des Blattes einer C4-Pflanze

C4-Pflanzen wie beispielsweise der Mais oder das Zuckerrohr sind Fotosynthesespezialisten, bei denen die Mesophyll- und Bündelscheidenzellen des Blattes (siehe Abb. 1) arbeitsteilig zusammenarbeiten, um das Kohlendioxid der Luft in Form von Zucker oder Stärke zu fixieren. Die an der C4-Fotosynthese beteiligten Gene müssen daher differenziell in den beiden Zelltypen exprimiert werden. Dafür sind die Steuerregionen der Gene verantwortlich. Die Expressionsspezifität der Steuerregionen kann man dadurch untersuchen, dass man sie mit einem Farbgen als Reportergen verschweißt und die Fusionsgene in die Pflanzen transformiert. Hier ist gezeigt, dass die Steuerregion des ppcA-Gens aus der C4-Pflanze Flaveria trinervia eine mesophyllspezifische Expression des blauen Farbgens bewirkt, während die Steuerregion des GLDPA-Gens nur in der Bündelscheide aktiv ist. Die Daten entstammen den Arbeiten von Gowik et al. (2004) und Engelmann et al. (2008).

im Proteinmolekül ändern können? Wie erkennen die Transkriptionsfaktoren ihre Bindestellen im Enhancer? Binden sie zufallsmäßig oder in einer definierten Reihenfolge, und helfen sie sich möglicherweise sogar dabei?

Um diese Fragen zu beantworten, sollte man den Proteinen bei der Arbeit zuschauen können. Das ist heutzutage möglich, wenn man ein konfokales Lasermikroskop besitzt und die Proteine, die man sehen will, zuvor markiert hat. Zur Etikettierung von Proteinen werden gerne Leuchtproteine wie das grün fluoreszierende Protein oder andere Vertreter dieser Gruppe verwendet. Das grün fluoreszierende Protein kann - seinem Namen entsprechend - grünes Licht aussenden, wenn es zuvor mit blauem Licht angeregt wurde. Das grün fluoreszierende Protein stammt übrigens aus einer Tiefseequalle, die das anregende Blaulicht selbst über eine chemische Reaktion erzeugt.

Die fluoreszierenden Proteine haben aber noch mehr im Angebot. Sie funktionieren erstaunlicherweise auch dann, wenn man sie in zwei Hälften teilt und diese getrennten Proteinhälften sich wieder zusammenlagern können. Diese Eigenschaft, aus zwei getrennten Proteinhälften die Gesamtfunktion des ursprünglichen Leuchtproteins rekonstituieren zu können, nutzt man aus, um das Bindungsverhalten von Proteinen in der lebenden Zelle zu untersuchen. Verschweißt man das erste Protein mit der einen Hälfte des Leuchtproteins und das zweite mit der anderen Hälfte, beobachtet man in der Zelle dort ein Leuch- 


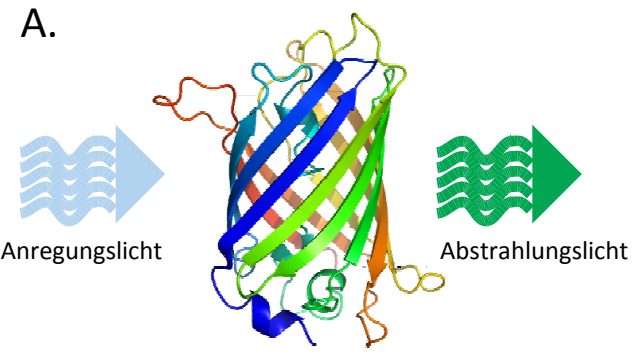

Leuchtprotein
B.

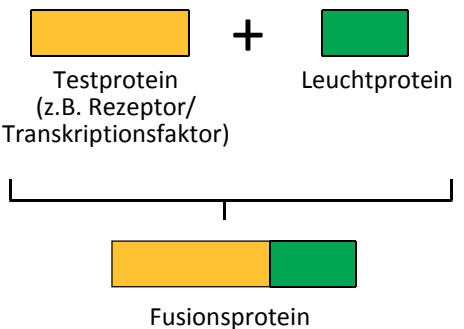

Abb. 6: Das grün fluoreszierende Protein als Handwerkszeug des Zellbiologen

Das grün fluoreszierende Protein ist der Prototyp einer mehr und mehr wachsenden Familie von Leuchtproteinen. Diese Proteine leuchten, wenn man sie mit Licht einer definierten Wellenlänge bestrahlt. Das grün fluoreszierende Protein beispielsweise bestrahlt man mit blauem Licht, und das Protein strahlt dann grünes Licht ab (Teil A). Andere Leuchtproteine strahlen gelb oder rot. Wenn man das grün fluoreszierende Protein auf gentechnischem Wege mit anderen Proteinen wie Rezeptoren oder Transkriptionsfaktoren verschweißt (Teil B), behält das grün fluoreszierende Protein seine Fähigkeit als Leuchtprotein. Mit Hilfe eines konfokalen Lasermikroskops kann man den Aufenthaltsort des grün fluoreszierenden Proteins und damit des Fusionspartners bestimmen (siehe Abb. 7).
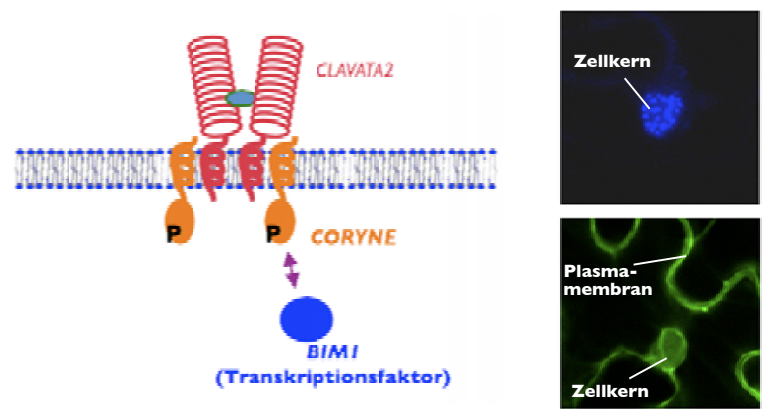

\section{BIM1:CFP}

CORYNE:GFP

Abb. 7: Eine pflanzliche Signalkette - wo befinden sich Rezeptoren und Transkriptionsfaktoren?

Das Signalprotein CORYNE ist Teil eines mehrteiligen Rezeptorkomplexes, der in der Plasmamembran der Zellen des Sprossapikalmeristems von Pflanzen angesiedelt ist. Das Fusionsprotein von CORYNE mit dem grün fluoreszierenden Protein (GFP) befindet sich dementsprechend in der Zellmembran. Das CORYNE-GFP-Fusionsprotein häuft sich aber auch im Zellkern an, wo sich auch der Transkriptionsfaktor BIM1 befindet. Es wird vermutet, dass CORYNE und BIM1 direkt miteinander wechselwirken. Die Daten wurden freundlicherweise von Univ.-Prof. Dr. Rüdiger Simon (Institut für Genetik) zur Verfügung gestellt.

ten, wo die beiden Proteine aneinander binden (Abb. 8). Diese oder auch andere ähnliche Techniken erlauben es, Signalnetzwerken bei ihrer Arbeit zuzuschauen und dabei auch die Dynamik des Systems zu erfassen. 


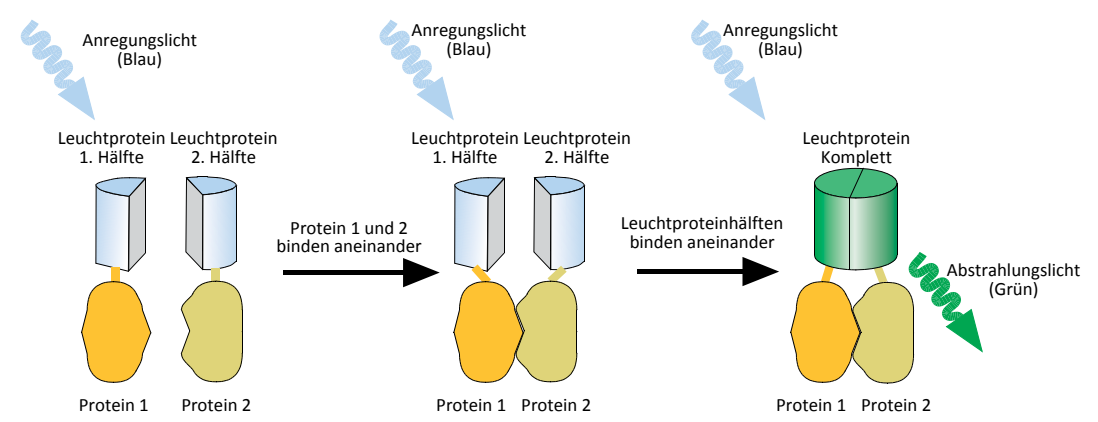

Abb. 8: Nachweis von Protein-Protein-Wechselwirkungen in der lebenden Zelle

\section{Resümee und Ausblick}

Wie Zellen verschieden werden und wie dieser Prozess auf der Molekülebene geregelt wird, ist eine hoch aktuelle Forschungsproblematik, die durch die neuen Untersuchungsmethoden noch an Attraktivität gewinnt. Konnte man früher Differenzierungsprozesse eher nur beschreiben, so ist jetzt das experimentelle Rüstzeug vorhanden, um Differenzierung auf dem mechanistischen Niveau zu erklären. Die Forschungsthematik des SFB 590 ist damit auch weiterhin zukunftsträchtig.

Im Juli 2008 ist der SFB 590 in seine dritte und letzte Förderperiode eingetreten. Die Gründerin und langjährige Sprecherin des SFB 590, Univ.-Prof. Dr. Elisabeth Knust, wurde 2006 an das Max-Planck-Institut für Genetik und Zellbiologie in Dresden berufen. Drei Nachwuchswissenschaftlerinnen und -wissenschaftler folgten Rufen auf Professuren an in- und ausländischen Universitäten: PD Dr. Andreas Wodarz nach Göttingen, PD Dr. Arno Müller nach Dundee und PD Dr. Ute Höcker nach Köln. Durch eine konsequente, zielgerichtete Berufungspolitik - fünf Neuberufungen auf W3- und W2-Stellen in den Jahren 2005 bis 2008 sind Teilprojektleiter im SFB - konnten diese Abgänge kompensiert werden, und der SFB 590 gewann ein neues Profil.

SFBs sollen die Forschungslandschaft einer Universität prägen und strukturieren. Das ist dem SFB 590 gelungen. Er schlug nicht nur eine Brücke innerhalb der MathematischNaturwissenschaftlichen Fakultät, nämlich zwischen der Biologie und der Chemie, sondern auch hinüber zur Medizinischen Fakultät. Der SFB 590 ist gegenwärtig der einzige ortsständige, lebenswissenschaftliche SFB, der aus der Mathematisch-Naturwissenschaftlichen Fakultät entstanden ist. SFBs dokumentieren die Fähigkeit einer Universität oder einer Fakultät, Forschungsaktivitäten zu einer attraktiven und aktuellen Problematik bündeln zu können. Nicht von ungefähr gelten sie daher als ein Erfolgskriterium einer guten Universitätspolitik. Im Jahr 2012 endet der SFB 590. Die Fakultät und die Universität sind daher gut beraten, schon jetzt daran zu denken, welches Forschungsgebiet einen neuen SFB tragen könnte. Die Erfahrung lehrt, dass SFBs nicht vom Himmel fallen, sondern in der Regel das Ergebnis einer zielgerichteten Berufungspolitik sind. Die Gelegenheit dafür ist günstig; sie sollte genutzt werden. 


\section{Literatur}

Engelmann, Sascha, Christian Wiluda, Janet Burscheidt, Udo Gowik, Ute Schlue, Maria Koczor, Monika Streubel, Raffaelo Cossu, Hermann Bauwe und Peter Westhoff (2008). „The gene for the P-subunit of glycine decarboxylase from the $\mathrm{C} 4$ species Flaveria trinervia: analysis of transcriptional control in transgenic Flaveria bidentis (C4) and Arabidopsis thaliana (C3)“, Plant Physiology 146, 1773-1785.

GowiK, Udo, Janet Burscheidt, Meryem Akyildiz, Ute Schlue, Maria Koczor, Monika Streubel und Peter Westhoff (2004). „Cis-regulatory elements for mesophyll-specific gene expression in the $\mathrm{C} 4$ plant Flaveria trinervia, the promoter of the $\mathrm{C} 4$ phosphoenolpyruvate carboxylase gene“", The Plant Cell 16, 1077-1090. 
